\title{
International Advertising Strategy In 'New' Asia: A Country-Of-Origin Approach On Standardization Vs. Customization
}

Meng, Juan (Gloria), Ph.D., Minnesota State University, Mankato, USA

Venkatapparao Mummalaneni, Ph.D., Virginia State University, USA

\begin{abstract}
This study revisited the debate concerning standardization vs. customization of the international advertising strategy from a Country-of-Origin (COO) approach. The objective here is to compare the perceptions of the exporting country and its products from the vantage point of different host countries, and to compare exporting country's self-image with the perceived images prevailing in the host countries. Further, the study also examines the images of search products and experience products across different countries. Through analyzing survey data collected from 189 Americans, 238 Chinese, and 236 Japanese consumers, we found that different host countries have significantly different perceptions of the same exporting country. Moreover, exporting country's self-image also largely varies from the host country's perception of the exporting country. Finally, differences in product image were found both for search and experience products. Therefore, customized advertising strategy is suggested in the "New" Asia, especially in the countries studied.
\end{abstract}

Keywords: international advertising; country-of-origin; self-image/perceived image

\section{INTRODUCTION}

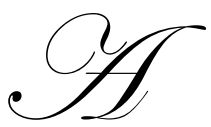

sia is a region characterized by multiple languages, religions and ethnicities, resulting in variegated values and lifestyles. However, marketing research and marketing knowledge of the complex Asian market and its diverse consumers are sorely lacking.

Moreover, Asia has been going through dramatic changes since the middle of the last century and without doubt became the "New" Asia. For instance, Japan experienced the miracle of economic development and became the second largest economy in the world after World War II. Additionally, China maintained a torrid pace of economic development, with more than 10\% annual GDP growth rate during the last several years. In fact, recent population and economic projections by the McKinsey group conservatively estimate that China will be at least the third largest consumer market by 2025. Other think-tanks are even more sanguine in their projections. They estimate that China will overtake Japan as the second largest consumer market as early as 2015 (Boston Consulting Group, 2007; Garner, 2005). The urban middle class of Chinese consumers is predicted to grow $76 \%$ to 612 million by 2025 (McKinsey Group, 2006). This rising middle class will be comprised of younger consumers, age 25 to 44 years old, and, in size, will be much larger than other affluent consumer segments in China (Farrell et al., 2006).

Unlike the last generation, the new generation in Asia, especially the "newly empowered middle class" in China, is less frugal and eager to engage in the consumption of branded and luxury products. This "New" Asia phenomenon speeds up the worldwide market competition and provides limitless opportunities for numerous businesses. It is obvious that Asia, especially "new" Asia, deserves more attentions from both researchers' and practitioner's standpoints. Therefore, this study focuses on advertising and promotion strategies in the "New" Asia and revisits the debate of standardization vs. customization of advertising message from a Country-of-Origin (COO) approach. 
Marketing literature has argued that $\mathrm{COO}$ significantly affects consumers' purchase of foreign products. However, it still remains unclear whether people from different host countries perceive the exporting country differently (e.g. Chinese consumes' perception of America vs. Japanese consumer's perception of America), whether people in the exporting country perceive their country differently than people from host countries (selfimage vs. perceived image; e.g., American consumers' perception of America vs. Chinese consumers' perception of America), and whether people perceive search products differently than experience products. Based on a series of comparisons among the three large economies, namely, USA, China, and Japan, this study attempts to assess the validity and the value of $\mathrm{COO}$ effect as a factor in international advertising strategy decision-making.

\section{LITERATURE REVIEW}

The debate on standardization vs. customization of advertising messages started during the 1960's with the question, "should multinational advertising be standardized or customized?" (Harris, 1994; Duncan and Ramaprasad, 1995). Although it has raged for more than four decades, the spread of free market policies and the opening of the world markets to international trade in the recent years have made this debate even more relevant today.

Standardization was defined in the literature as "keeping one or more of the three basic components of a multinational advertising campaign — strategy, execution, language - the same" (Duncan and Ramaprasad, 1995, p. 55). During this debate, many researchers emphasized the benefits of standardizing international advertising. In fact, as early as 1961, Elinder argued that companies should use standardized campaigns in order to become more efficient. A considerable amount of research supported this view and identified additional benefits, such as convenience (Thorelli, 1985) and the maintenance of a consistent brand image (Taylor and Okazaki, 2006).

On the other hand, there were researchers who questioned the feasibility of advertising standardization in different countries from the early times, and moved the discussion to the limitations of advertising standardization (Bartels, 1968). Consequently, the question was changed from "should multinational advertising be standardized or customized?" to "In what situations and to what extent should multinational advertising be standardized?" Many studies suggested that standardization should not be a universal policy (e.g., Tse, Belk, and Zhou, 1989; Weinberger and Spotts, 1989; Tansey Hyman, and Zinkhan, 1990; Frith and Wesson, 1991; Taylor and Okazaki, 2005) and made efforts at understanding the factors that determine the level of standardization and the magnitude of their impact (Duncan and Ramaprasad, 1995; Papavassiliou and Stathakopoulos, 1997).

Arguably, the most comprehensive study about factors influencing the level of standardization was conducted by Okazaki, Taylor, and Zou (2006). This study summarized previous research findings, proposed a model revealing the underlying structure of the level of standardization, and empirically tested the model fit and hypotheses. The antecedent factors were specified as environmental factors including customer similarity, market similarity, advertising infrastructure, and the level of competition, strategic factors including global strategic orientation, perceived cost savings, cross-border segmentation, and global IMC, level of control factor, size of the subsidiary factor, and finally, the international experience factor.

While it is accurate to state that the model proposed in the above study provides a relatively comprehensive picture of the determinants of the level of standardization, it is also fair to point out that there are some deficiencies. Three of them are discussed below.

The first deficiency is that the extant literature overlooked whether consumers in different host countries hold the same view of the exporting country and exporting country's products. Consumer behavior theories have incorporated sophisticated concepts of information processing paradigm from psychology and suggest that consumers make decisions based on their existing knowledge and external stimuli (Lynch and Srull, 1982). There is consensus in the marketing literature that consumers' reactions to adverting are the consequence of stimuli (advertising message) working on their current (existing) belief structures. In order to elicit the same consumer response from different host countries through standardized advertising, the obvious precondition is that host countries ought to hold the same beliefs and have the same image about the exporting country and its products. In 
other words, if the perceived image of the exporting country is identical or similar across different host countries, standardized advertising is feasible; otherwise, localized (customized) advertising should be considered.

Due to the complex historical, cultural, economical, political, and geographical factors involved, it is hard to believe that different host countries will hold the same image of an exporting country. However, research examining the differences in the perceived images of exporting country among different host countries is rarely seen in the marketing literature.

The second deficiency is being blind to the differences between self-image and perceived-image. Because of the lack of sufficient knowledge regarding perceived image, marketers and researchers of international advertising tend to assume that consumers in the host country see the exporting country as they themselves see it. In fact, it is difficult to find literature on the gap between a country's self-image and its image among consumers in other countries. More seriously, it is in human nature that we tend to use ideal-image in stead of objective self-image in many situations, thereby giving rise to the possibility of differences between the perceptions of consumers in the exporting and host countries.

Ignoring the gap between country's self-image and perceived image could be dangerous. According to the attribution theory, the persuasiveness of a message is adversely affected if the recipient infers a bias in the message source or the communicator, giving rise to skepticism (Balasubramaniam, 1994; Ford, Smith, and Swasy, 1990). Therefore, if you take it for granted that consumers in foreign country see you in the same way you see yourself, and provide a message deviating from foreign consumers' beliefs (e.g., if consumers in the host country think the exporting country is less industrious, but you provide a hard-working image in your ad.), your advertising will be perceived as biased, exaggerating, or even deceptive, and could provoke consumers' negative reactions towards your brands and products. Furthermore, this unpleasant experience with the advertising will hurt the perceived-image of your country, which will negatively affect your future business in this country.

Besides the risk discussed above, ignoring this gap may also lead to the loss of some good opportunities. Consumers are more likely to recall novel or unexpected information than something that is expected (Balasubramaniam, 1994, Lynch \& Srull, 1982). For example, if consumers in the host country do not think the exporting country is very creative, when the exporting country designs a creative ad., this will attract viewers' attention and increase their recall levels. Here, the gap between self-image and perceived-image became an advantage which could be profitably employed in international advertising strategy building.

Therefore, no matter whether the marketers want to avoid the skepticism caused by the inconsistent image or to take advantage of a novel image, they must know whether the self-image is different from perceived image and how different they are. Unfortunately, we know little about these differences. However, there is plenty of evidence about the gap between individual consumers' ideal-image (self-image) and actual-image. Therefore, it is fair to assume that country's self-image would also differ from its actual (perceived)-image. Therefore, there is a need to clarify whether there are differences between country's self-image and perceived image (by foreign customers) and the nature of these differences.

Finally, the third deficiency is that previous research failed to consider search, experience, and credence properties of products separately when discussing the international advertising strategy. Economics of Information literature predicts that customers would be more skeptical of information they cannot verify. Moreover, Ford et al. (1990) also found different levels of skepticism depending on whether the product has search, experience or credence attributes. Therefore, we hypothesize that consumers in different host countries have a consistent image of search products but an inconsistent image of experience products.

The study presented here attempts to overcome these deficiencies by taking another factor into consideration-Country-of-Origin (COO) Effect, defined as an extrinsic product attribute indicating the country where a product is made, assembled, or both, from which the consumer makes inferences about value or quality.

Over the years, $\mathrm{COO}$ effects have been documented extensively in the marketing literature (Bilkey and Nes, 1982; Erickson, Johansson, and Chao, 1984; Han, 1989; Hastak and Hong, 1991; Hong and Wyer, 1989, 1990). 
In some ways, the concept of "country-of-origin" is similar to the concept of branding, in that the name of the country becomes associated with the brand's name and consumers' attitudes toward the country-of-origin becomes entangled with their attitudes toward the product. Ultimately, like brand name, a product or service's country-oforigin is used by consumers as a cue in the consumer decision-making process.

Parameswaran and Pisharodi (1994) integrated the previous studies and identified six dimensions of the COO effect. Five dimensions were based on initial research by Parameswaran and Yaprak (1987), which proposed general country attribute (GCA) and general product attribute (GPA) dimensions of the COO effect. Parameswaran and Pisharodi (1994) subsequently divided GCA into two dimensions, the people facet (GCA1) and the interaction facet (GCA2), and GPA into three dimensions, negative (or undesirable) attributes (GPA1), positive (or desirable) attributes relating to promotional/distributional image (GPA2), and positive (or desirable) attributes relating to product image (GPA3). A sixth dimension called specific product attribute (SPA) was derived from Bilkey and Nes's (1982) research.

However, in the international advertising strategy arena, there is a dearth of studies examining the COO effect. We could identify only one study mentioning the $\mathrm{COO}$ effect but it neither incorporated it into a model nor tested it empirically. Borrowing the concept of $\mathrm{COO}$ effect, especially taking advantage of the established scales, this study attempts to attain the following three objectives corresponding to the three deficiencies discussed above.

\section{RESEARCH OBJECTIVES}

The present research focuses on country and product images. Specifically, there are three objectives. One is to test whether consumers in different host countries perceive the exporting country in the same way. In this study, we compare America's image as perceived by the Chinese customers and Japanese customers as well as Japan's images as perceived by the Chinese customers and American customers.

The other objective is to explore the gap between a country's perceptions of its native customers and by the foreign customers, i.e., the gap between self-image and perceived image. The last objective is to test specific product images and to see whether the consumers in different countries have consistent perceptions on the search products but different perceptions on the experience products. For this purpose, we selected Sony's CD player as a search product and McDonald's meal as an experience product because these two products are equally popular across several countries.

H1: Consumers in different host countries have different perceptions of the exporting country and its products.

H2: Exporting county's consumers have different self-image than the image perceived by the consumers in the host country.

H3: Consumers in different countries have a consistent image of search products but an inconsistent image of experience products.

\section{METHODOLOGY}

\section{Measurement Of The Constructs In The Model}

The proposed measurement model was applied in two product contexts - Sony's CD player and McDonald's meal. Six latent constructs were proposed to underlie the measurement items; 10 items measured general country attributes (GCA: 2 factors) and 19 items measured general product attributes (GPA: 3 factors). All items were adopted from Parameswaran and Yaprak's (1987) work. Measures of specific product attributes (SPA) were slightly modified from Bilkey and Nes (1982), corresponding to the different products tested. Seven items were employed in the Sony CD purchase context and six items were used to measure SPA in the McDonald's meal service context. Respondents indicated their agreement on all items using a five-point Likert-type scale, with 1 indicating "strongly disagree" and 5 indicating "strongly agree." Some items were reverse-coded, so that, for all subscales, higher values indicated higher agreement. See Appendix 1 for measurement items. 


\section{RATIONALE FOR USING SUBJECTS' NATIVE LANGUAGES}

American respondents completed the survey in English, whereas the Chinese respondents completed the survey in Chinese. Although the use of a common language for all respondents helps overcome potential languagebased response biases common to multicultural research (Dawar and Parker, 1994; Douglas and Craig, 1983), the present study does not follow that approach for a specific reason. Most of the cultures studied in previous research were western cultures, with respondents from all cultures fluent in English. Subjects in the present study, however, were recruited from China and Japan, where many of the respondents are not fluent in English. Administering the survey in English would cause problems in terms of subjects' understanding of questions and perhaps decrease the degree of insight into country-of-origin effects.

\section{Questionnaire Translation And Validation}

With the aid of an English-Chinese dictionary, the questionnaire was initially translated by the author who is a Chinese native and whose first language is Chinese. Therefore, the initial translation of Chinese version was expected to not only convey the meaning of the original English version questionnaire, but also be communicable to the consumers in China.

In order to precisely transfer the meaning of English version questionnaire to Chinese, the Chinese language version was back translated into English by a native Chinese language speaker who earned her MBA degree at an American university. In order to avoid bias, the original English version questionnaire was not shown to the translator till she finished the back translation.

Then these two English version questionnaires - the original version and the version back translated from Chinese-were validated by a management professor who earned his Ph. D degree at an American University and for whom English is his native language. One major and two minor discrepancies were identified. The Chinese version questionnaire was later revised by the author based on these comments

The revised Chinese version questionnaire was sent to China via E-mail. Several of the author's relatives and friends examined it thoroughly and provided numerous suggestions regarding both word usage and sentence structure. These suggestions were selectively accepted by the author, and the Chinese version of the questionnaire was further revised and refined. Through this iterative and intensive process of revision, the questions asked in both English and Chinese version questionnaires were deemed to be equivalent.

Japanese version was translated by a Japanese speaker and was examined and validated by a Japanese professor who earned a Ph. D. degree in Linguistics. Following the same revision process, the Japanese version of the questionnaire was also deemed to be equivalent to the original English version. The questionnaire is shown in Appendix 1.

\section{Data Collection And Sample Characteristics}

Questionnaires were distributed to students enrolled in undergraduate marketing courses at a large public university in the Midwest. Subjects were asked to imagine that they were planning to buy a CD player for their own use or consuming a meal at McDonald's. One hundred and eighty-nine questionnaires were collected, but after eliminating surveys with missing data, 172 valid responses remained. The average age of sample respondents was 22.4 , and the gender of the respondents was well-balanced (51.7\% male and $48.3 \%$ female).

Data collection in China was handled by a group of the author's relatives and friends. Questionnaire was sent to China via email and copied in Anshan, a medium size city in Northern China. Questionnaires were distributed to students at a major university in that city. This is a comprehensive four year university with an emphasis on economics and business. Students were given an explanation of the purpose and the requirements of the study and asked to fill out the questionnaire during class time. The questionnaires were collected immediately after students filled them. 
Questionnaires collected from China were sent through airmail to America, and the author was responsible for data coding and quality assurance. Two invalid responses were deleted from the Chinese dataset, and 17 cases of international student responses were deleted from the American dataset as well. The results of descriptive data analysis for these two datasets are summarized below.

Data collection in Japan followed the same procedure as that in China. Totally 236 questionnaires were collected from a comprehensive university close to TOKYO, and 222 of them are valid. This sample consists $47.5 \%$ of male and $52.5 \%$ of female respondents, with the average age of 22.9. Sample characteristics among the three cultures are summarized in Table 1.

Table 1

\section{Data Description and Demographic Information}

\begin{tabular}{|c|c|c|c|}
\hline & American & Chinese & Japanese \\
\hline Total & 189 & 238 & 236 \\
\hline Deleted & 17 & 2 & 14 \\
\hline Valid & 172 & 236 & 222 \\
\hline Age & 22.4 & 22.2 & 22.9 \\
\hline Gender & $51.7 \%(\mathrm{M})$ vs. $48.3 \%(\mathrm{~F})$ & $23.8 \%(\mathrm{M})$ vs. $76.2 \%(\mathrm{~F})$ & $47.5 \%(\mathrm{M})$ vs. $52.5 \%(\mathrm{~F})$ \\
\hline
\end{tabular}

\section{ANALYSIS AND RESULTS}

First of all, a group of subscales was created for the various $\mathrm{COO}$ constructs for each product. Then ANOVA tests were run on these COO constructs (images) of USA and Japan across all three countries. As shown in Tables 2 and 3, all the constructs pertaining to the USA and Japan were perceived differently by Chinese, Japanese, and American customers ( $\mathrm{p}<.01)$ except GPA1 dimension of USA $(\mathrm{F}=2.40, \mathrm{p}=.09)$. It is obvious that in general, consumers from different countries hold significantly different images of a certain country and its products. Therefore, a group of t-tests was further conducted in order to examine the differences between the perceptions of consumers from each pair of countries involved. These t-tests not only examine the differences in the image of an exporting country between consumers from different host countries, but also the differences between self-image of an exporting country and its perceived image in the host countries.

Table 2

Mean Comparisons of America's Image

\begin{tabular}{|c|c|c|c|c|}
\hline & ANOVA & \multicolumn{3}{|c|}{ Independent Sample T Test } \\
\hline & (Three group comparison) & America - China & America - Japan & China - Japan \\
\hline GCA1 & $45.30^{* *}$ & $2.55^{*}$ & $9.24^{* *}$ & $7.17^{* *}$ \\
\hline GCA2 & N/A & N/A & N/A & $-5.58^{* *}$ \\
\hline GPA1 & 2.40 & -1.13 & $-2.06^{*}$ & -1.29 \\
\hline GPA2 & $59.56^{* *}$ & $10.59^{* *}$ & $8.83^{* *}$ & .56 \\
\hline GPA3 & $137.11^{* *}$ & $2.67^{* *}$ & $14.99^{* *}$ & $14.07^{* *}$ \\
\hline SPA_McD & $34.25^{* *}$ & $-5.79^{* *}$ & 1.91 & $7.68^{* *}$ \\
\hline
\end{tabular}

Symbols used in the tables

** Significant at .01 level

* Significant at .05 level

NA Not Applicable 
Table 3

Mean Comparisons of Japan's Image

\begin{tabular}{|c|c|c|c|c|}
\hline & ANOVA & \multicolumn{3}{|c|}{ Independent Sample T Test } \\
\hline & (Three group comparison) & America - China & America - Japan & China - Japan \\
\hline GCA1 & $64.30^{* *}$ & $11.09^{* *}$ & $10.40^{* *}$ & -.81 \\
\hline GCA2 & N/A & $15.29^{* *}$ & N/A & N/A \\
\hline GPA1 & $36.53^{* *}$ & -1.90 & $6.99 * *$ & $7.79 * *$ \\
\hline GPA2 & $21.83^{* *}$ & $6.69^{* *}$ & $3.09^{* *}$ & $-2.81^{* *}$ \\
\hline GPA3 & $23.14^{* *}$ & $6.29 * *$ & .90 & $-4.85^{* *}$ \\
\hline SPA_CD & $32.27^{* *}$ & $8.22^{* *}$ & $5.46^{* *}$ & $-2.18^{*}$ \\
\hline
\end{tabular}

Symbols used in the tables

** Significant at .01 level

* Significant at .05 level

NA Not Applicable

\section{Perceived Image Differences Between Different Host Countries (H1)}

According to Table 2, Chinese and Japanese have relatively consistent perceptions of American products; in fact, neither GPA1 nor GPA2 was significant at .05 level, although GPA3 was significant $(\mathrm{t}=14.07, \mathrm{p}<.01)$. However, it may be concluded that Chinese and Japanese consumers perceive America and the American people quite differently since both GCA1 and GCA2 were significant ( $\mathrm{p}<.01)$. Moreover, through the mean comparison, we can see that Chinese consumers perceive America and American people more favorably than the Japanese (Table 4, Figure 1).

Table 4

Mean Scores of America's Image

\begin{tabular}{|c|c|c|c|c|c|c|}
\hline & GCA1 & GCA2 & GPA1 & GPA2 & GPA3 & SPA \\
\hline American & 3.59 & N/A & 2.77 & 3.91 & 3.31 & 2.99 \\
\hline Chinese & 3.46 & 2.33 & 2.82 & 3.41 & 3.20 & 3.32 \\
\hline Japanese & 3.09 & 2.69 & 2.88 & 3.38 & 2.58 & 2.86 \\
\hline
\end{tabular}

In addition, t-tests were conducted to compare American and Chinese consumer perceptions of Japan and Japanese product (Table 3). All the COO dimensions were significantly different between Chinese and American consumers $(\mathrm{p}<.01)$ except GPA1 which was not statistically significant $(\mathrm{t}=1.90, \mathrm{p}>.05)$. Moreover, Americans have more favorable perceptions of Japan, its people and products than the Chinese (Table 5, Figure 2).

Table 5

Mean Scores of Japan's Image

\begin{tabular}{|c|c|c|c|c|c|c|}
\hline & GCA1 & GCA2 & GPA1 & GPA2 & GPA3 & SPA \\
\hline American & 3.88 & 2.98 & 2.76 & 3.71 & 3.55 & 3.78 \\
\hline Chinese & 3.25 & 2.17 & 2.86 & 3.35 & 3.24 & 3.29 \\
\hline Japanese & 3.30 & N/A & 2.36 & 3.53 & 3.50 & 3.48 \\
\hline
\end{tabular}

So far, the above results partially supported H1: exporting country's image and its product's image do vary across different host countries. This suggests that exporting country should use customized advertising strategies in different host countries, at least in the countries tested here, in order to reach the same advertising goal. 


\section{Self-Image vs. Perceived-Image (H2)}

Next, t-tests were also conducted in order to see whether and how exporting country's self-image differs from host country's perception of the same image. Regarding America and American products, both Chinese and Japanese perceived them differently than American people perceiving themselves (self-image), except that the Chinese have the same perception of GPA1 is consistent with American's self-image ( $t=-1.13, \mathrm{p}>.05)$ (Table 2).

Likewise, similar results were obtained regarding the perceptions of Japan and Japanese products (Table 3). In fact, American and Chinese consumers also perceive Japan and Japanese products differently than Japan's selfimage ( $\mathrm{p}<.01)$. Two exceptions were also found: Americans' perception of GPA3 and Chinese perception of GCA1 were consistent with Japan's self-image.

These results generally supported $\mathrm{H} 2$ and suggest to researchers and practitioners that self-image is different from perceived image. We cannot assume that people see us in the way we see ourselves, when developing advertising messages for international markets.

It is also interesting to note that American's self-image is generally more favorable than host countries' (China and Japan in this case) perceived image. On the other hand, Japan's self-image is usually lower than the perceived image by American and Chinese (Table 4 and 5, Figure 1 and 2).

\section{Search Product vs. Experience Product (H3)}

Finally, ANOVAs were conducted on the SPA dimension of both search product (CD player) and experience product (McDonald's meal). Consistent with hypothesis $3(\mathrm{H} 3)$, there are statistically significant differences among the perceptions of McDonald's meal across the three countries ( $F=34.25, \mathrm{p}<.01)$ (Table 2). This result supports one half of $\mathrm{H} 3$ - consumers in different countries perceive experience product differently. However, consumers from China, Japan, and the US perceived Sony's CD player differently as well $(\mathrm{F}=32.27, \mathrm{p}<.01)$, (Table 3 ), contradicting the other half of $\mathrm{H} 3$ - Consumers in different countries have a consistent image of search products. Therefore, $\mathrm{H} 3$ is partially supported.

\section{Conclusions And Implications}

Country-of-origin (COO) effect has been studied in the context of the product strategy and the pricing strategy in previous research, but has not been explored in the context of promotion (especially advertising) strategy. In the decision regarding the standardization vs. customization of international advertising, COO effect should be incorporated as an important factor.

More specifically, if the $\mathrm{COO}$ effect is similar among host countries, standardization is possible or maybe even preferred. Otherwise, customized advertising strategy should be undertaken in different host countries. Therefore, the present research would lend support to the strategy of customizing international advertising since the results show that perceptions of the origin country vary across the several host countries.

Second, because we found that the self-image (e.g., American consumers' view of America) is significantly different from the images perceived by consumers from other countries (e.g. Chinese consumers' view of America, or Japanese consumers' view of America), the present study highlights the importance of conducting research on $\mathrm{COO}$ effect instead of taking it for granted that foreigners' view of your country is similar to how you view your own country. This calls for more studies on $\mathrm{COO}$ effect, especially from the standpoint of international advertising strategy.

Finally, our hypothesis that search products have a consistent image across different countries while experience products have different images across different countries (H3), was not supported by the results of this study. Therefore, not only experience products but also search products should consider using customized advertising and promotion strategies, especially in the two Asian countries studied. 


\section{AUTHOR INFORMATION}

Juan Meng holds the Ph.D. in Marketing from Southern Illinois University - Carbondale. She is Assistant Professor of Marketing at Minnesota State University - Mankato.

Venkat Mummalaneni holds the $\mathrm{Ph}$. D. in Marketing from Pennsylvania State University. He is professor and chair of management and marketing department at Virginia State University.

\section{REFERENCES}

1. Balasubramaniam, S.K. (1994), "Beyond advertising and publicity: hybrid messages and public policy issues", Journal of Advertising, Vol. 23 No. 4, pp. $29-46$.

2. Bikey, W.J. and Nes, E. (1982), “Country-of-origin effects on product evaluations", Journal of International Business Studies, Vol. 13 No. Spring/Summer, pp. 89-99.

3. Dawar, N. and Parker, P. (1994), "Marketing universals: consumers' use of brand name, price, physical appearance, and retailer reputation as signals of product quality", Journal of Marketing, Vol. 58 No. April, pp. 81-95.

4. Douglas, S.P. and Craig, C.S. (1983), International marketing research, Englewood Cliffs, NJ: PrenticeHall, Inc.

5. Duncan, T. and Ramaprasad, J. (1995), "Standardized multinational advertising: the influencing factors", Journal of Advertising, Vol. 24 No. 3, pp. 55-68.

6. $\quad$ Elinder, E. (1961), "How international can advertising be?" International Advertiser No. December, pp. 1720.

7. Erickson, G.M. and Johansson, J.K. (1985), "The role of price in multi-attribute product evaluations", Journal of Consumer Research, Vol. 12 No. September, pp. 195-199.

8. Frith, K.T. (1988), "More than we bargained for: the impact of consumer culture in southeast asia", National Conference of the Association for Education in Journalism and Mass Communication, Portland, OR, August.

9. Ford, G.T., Smith, D.B., and Swasy, J.L. (1990), “Consumer skepticism of advertising claims: testing hypotheses from economics of information", Journal of Consumer Research, Vol. 16 No. 4, pp. 433-441.

10. Han, C. M. (1989), “Country image: halo or summary construct?” Journal of Marketing Research, Vol. 26 No. May, pp. 222-229.

11. Hastak, M. and Hong. S. (1991), "Country-of-origin effects on product quality judgments: an information integration perspective", Psychology and Marketing, Vol. 8 No. Summer, pp. 129-243.

12. Harris, G. (1994), "International advertising standardization: what do the multinationals actually standardize?" Journal of International Marketing, Vol. 2 No. 4, pp. 13-30.

13. Hong, S. and Wyer, R.S. (1989), "Effects of country-of-origin and product-attribute information on product evaluation: an information processing perspective", Journal of Consumer Research, Vol. 16 No.

September, pp. 175-188.

14. Lynch, J.G. and Srull, T.K. (1982), "Memory and attentional factors in consumer choice: concepts and research methods", Journal of Consumer Research, Vol. 9, pp. 18-37.

15. Okazaki, S., Taylor, C.R., and Zou, S. (2006), “Advertising standardization's positive impact on the bottom line”, Journal of Advertising, Vol. 35 No. 3, pp. 17-33.

16. Papavassiliou, N. and Stathakopoulos, V. (1997), "Standardization versus adaptation of international advertising strategies: towards a framework”, European Journal of Marketing, Vol. 31 No. 7, pp. 504-527.

17. Parameswaran, R. and Yaprak, A. (1987), "A cross-national comparison of consumer research measures, Journal of International Business Studies, Vol. 18 No. Spring, pp. 35-49.

18. Tansey, R., Hyman, M.R., and Zinkhan, G.M. (1990), "Cultural themes in brazilian and U.S. auto ads: a cross-cultural comparison", Journal of Advertising, Vol. 19 No. June, pp. 30-39.

19. Taylor, C.R. and Okazaki, S. (2006), "Who standardizes advertising more frequently, and why do they do so? a comparison of U.S. and Japanese subsidiaries' advertising practices in the European Union”, Journal of International Marketing, Vol. 14 No. 1, pp. 98-120. 
20. Tse, D.K., Belk, R.W., and Zhou, N. (1989), "Becoming a consumer society: a longitudinal and crosscultural content analysis of print ads from Hong Kong, the People's Republic of China, and Taiwan", Journal of Consumer Research, Vol. 15 No. March, pp. 457-462.

21. Weinberger, M.G. and Spotts, H.E. (1989), "A situational view of information content in TV advertising in the USA and UK”, Journal of Marketing, Vol. 52 No. October, pp. 81-95.

Figure 1

America's Image

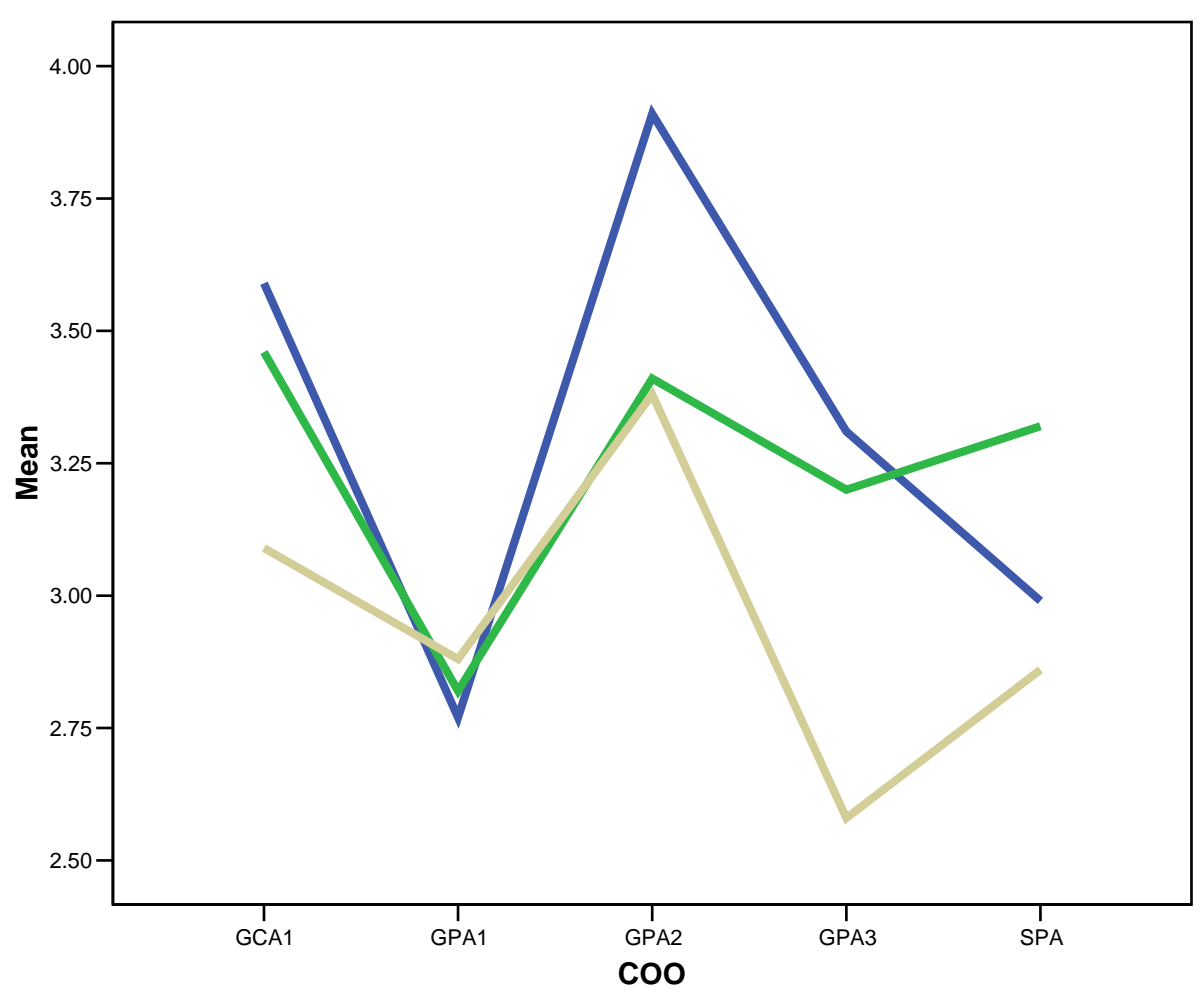

American
Chinese
Japanese 
Figure 2

Japan's Image

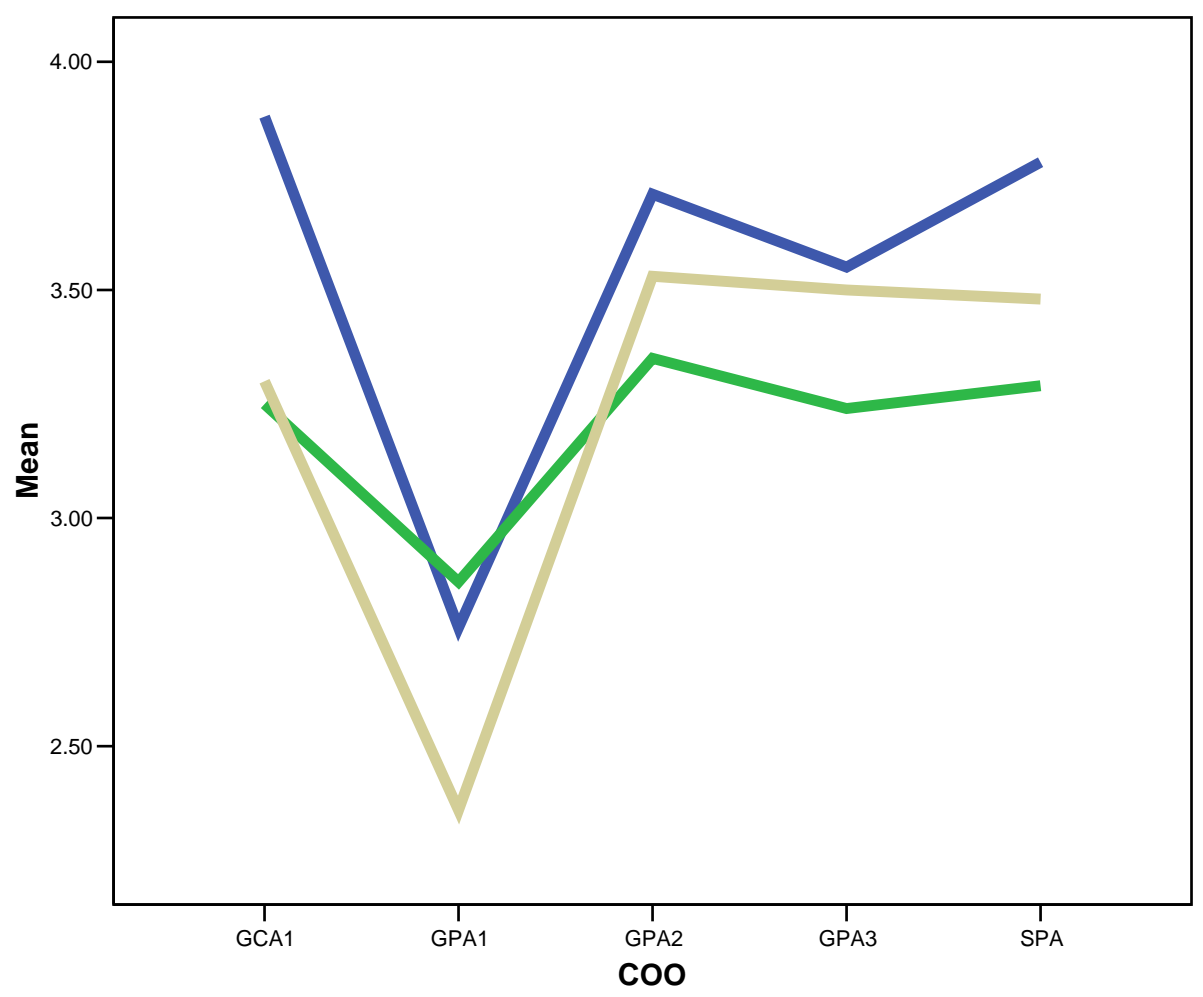

American

Chinese

Japanese 


\section{APPENDIX 1 \\ Instrument Labels}

\begin{tabular}{|c|c|}
\hline About Japan/America, I think & Factors \\
\hline 1. People are well-educated. & \multirow{8}{*}{ GCA1 } \\
\hline 2. Places emphasis on technical/vocational training. & \\
\hline 3. People are hard-working. & \\
\hline 4. People are creative. & \\
\hline 5. People are friendly and likeable. & \\
\hline 6. Technical skills of workforce are high. & \\
\hline 9. People are motivated to raise living standards. & \\
\hline 10. People are proud to achieve high standards. & \\
\hline 7. It's friendly toward my country in international affairs. & \multirow{5}{*}{ GCA2 } \\
\hline 8. It actively participates in international affairs. & \\
\hline 11. It has similar political views to my country's. & \\
\hline 12. It's economically similar to my country. & \\
\hline 13. It's culturally similar to my country. & \\
\hline 14. Products are unreasonably expensive. & \multirow{6}{*}{ GPA1 } \\
\hline 15. Products are imitations, not innovations. & \\
\hline 16. Products need frequent repairs. & \\
\hline 17. Products are hard to service here. & \\
\hline 18. Products are cheaply made consumer items. & \\
\hline 19. Products are not attractive. & \\
\hline 20. Products are distributed worldwide. & \multirow{4}{*}{ GPA2 } \\
\hline 21. Products are intensively advertised here. & \\
\hline 22. Advertising of products is informative. & \\
\hline 23. Products are easily available. & \\
\hline 24. Country produces highly technical products. & \multirow{9}{*}{ GPA3 } \\
\hline 25. Country is known for "luxury" products. & \\
\hline 26. Products are made with meticulous workmanship. & \\
\hline 27. Concerned with product performance, not appearance. & \\
\hline 28. Products are marketed in a wide range of styles. & \\
\hline 29. Products are long-lasting (durable). & \\
\hline 30. Products are known mainly for industrial products. & \\
\hline 31. Products are good value. & \\
\hline 32. Products are considered prestigious products. & \\
\hline
\end{tabular}

\section{I think Sony's CD player}

1. Has high-quality sound.

2. Made with good workmanship.

3. Is attractively styled.

4. Accessories/parts are easily available.

5. Has more feature than competitors' products.

6. Servicing is easily available.

7. Is good value for the money.

I think McDonald's restaurants

1. Provide high-quality meal.

2. Are served by the staff with good training.

3. Have attractive style.

4. Are easily available.

5. Provide more and/or better services than competitors do.

6 . Is good value for the money. 